\title{
Perceptual defense and vigilance: Prediction from the Byrne Scale of Repression-Sensitization
}

L. D. HUTT, MEMPHIS STATE UNIVERSITY

J. P. ANDERSON, UNIVERSITY OF ARKANSAS

Thresholds of nonsense syllables which had been paired previously with taboo words were found to be significantly higher in a group of college students identified as Repressers than nonsense syllables which had been paired previously with neutral words. These findings were interpreted as supporting a perceptual defense hypothesis. A mechanism of perceptual defense, the pupil response to emotional stimuli, was suggested.

Stimulus frequency and response suppression have been demonstrated to be powerful variables influencing the recognition thresholds of words and both have been offered as alternatives to a perceptual defense hypothesis in explaining the heightened thresholds to taboo words (Minard, 1965). Although several studies suggest that a perceptual defense notion is not entirely superfluous, perceptual defense by no means has the status of an independent phenomenon. The problem, and the purpose of this experiment, is to demonstrate perceptual defense under conditions in which stimulus frequency and response suppression are controlled.

Method

Since several studies have indicated that individual differences in response to threat or anxiety are important (Bruner \& Postman, 1947; Lazarus et al, 1951) in determining recognition thresholds of taboo words, the Byrne Repression-Sensitization Scale (1961) was used in selection of Ss. From a total of 185 students to which the R-S Scale was administered, the 20 highest scoring students (the Repressers) and the 20 lowest scoring students (the Sensitizers) were selected as Ss. It was predicted that Repressers would show perceptual defense and Sensitizers would show perceptual vigilance. Half the Ss from each group were assigned to one of two experimental conditions: Neutral or Taboo. Subjects in the Taboo condition learned the following nonsense syllable-word pairs: HIF-PENIS, MEZ-BITCH, SAJ-QUEER, XAPRAPE, ZER-KOTEX. The same nonsense syllables were used in the Neutral condition and the following pairs were learned: HIF-FRIEND, MEZ-HONOR, SAJ-APPLE, XAP-WATER, ZER-MONEY. In both conditions the pairs were presented, using a pairedassociate technique, for 20 trials on the memory drum. The syllable served as the stimulus and the word as the response. Following learning trials the syllables, not the words, were presented tachistoscopically using an ascending method of limits. The series was begun at an exposure interval of $.01 \mathrm{sec}$ and proceeded to intervals of .02, .04, .10, .20,. .40, and $1.00 \mathrm{sec}$. The series was terminated at the exposure duration which yielded $100 \%$ recognition. All syllables were presented in a different random order at each exposure interval. For each $\mathrm{S}$ the thresholds of the five syllables were averaged, yielding a mean recognition threshold for each $\mathrm{S}$. A median of mean recognition threshold was then calculated.

\section{Results}

Median recognition thresholds for the two groups (Repressers vs Sensitizers) under the two conditions (Neutral vs Taboo) are presented graphically in Fig. 1. Since heterogeneity of variances was present, a nonparametric median test was used in the statistical analysis. The median threshold of $.056 \mathrm{sec}$ for Repressers in the Taboo condition was found to be significantly higher (alpha $=.01)$ than the median threshold of $0.24 \mathrm{sec}$ for Repressers in the Neutral condition. No other comparisons were statistically significant.

\section{Discussion}

These data appear to indicate that perceptual defense does occur to taboo stimuli even with word frequency and response suppression controlled. There is no reason to suppose that $S$ should suppress his

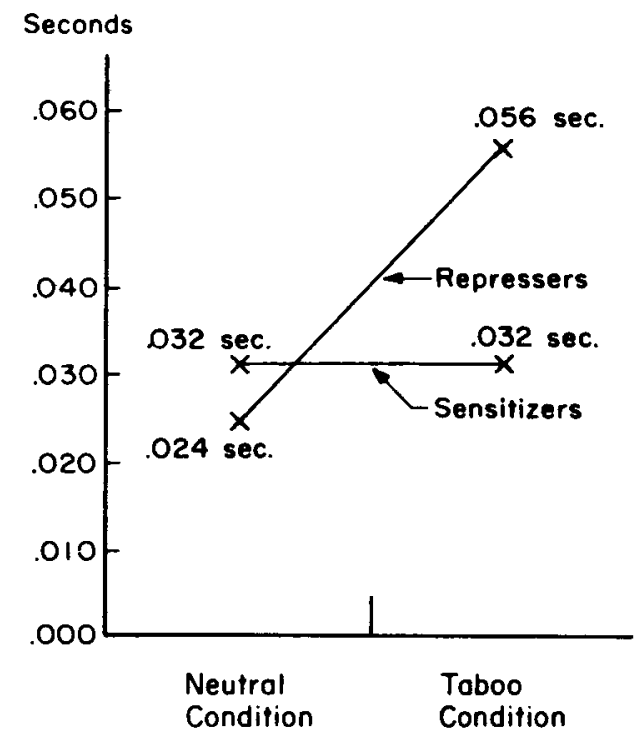

Fig. 1. Graph of median thresholds of paired syllables. 
verbalization of the nonsense syllable due to embarrassment, and since all Ss viewed identical nonsense syllables, no threshold variation may be attributed to stimulus frequency. The possibility that the frequency of the word, rather than its emotionality, generalized to the nonsense syllable did present itself and an experiment was conducted by Bradley (1965) to evaluate that possibility. Those findings indicate that thresholds of syllables previously paired with high frequency neutral words do not differ significantly from thresholds of syllables which have been previously paired with low frequency neutral words.

A Mechanism of Perceptual Defense? Even though several studies, including the one reported here, have indicated that perceptual defense does occur independently of response suppression and stimulus frequency, it is probable that perceptual defense and vigilance will continue to be viewed with considerable skepticism until a meaningful mechanism of perceptual blocking is demonstrated. The illogical and teleological flavor of the perceptual defense hypothesis has undoubtedly contributed greatly to the blemished history of the concept as have the findings supporting alternative hypotheses.

One plausible mechanism of perceptual defense is the pupil response to emotional stimuli, investigated recently by Hess (1965) and Hess \& Polt (1960). These authors have found that, in general, the pupil dilates to pleasant stimuli and contracts to unpleasant stimuli. It seems reasonable to suppose that the taboo words used in perceptual defense experiments initiate pupil contraction. With the pupil contracted and less light impinging on the retina, one would expect the recognition threshold to be heightened, i.e., perceptual defense. Such a process also offers an explanation of the overestimation of coin sizes found by Bruner \& Goodman (1947). One would expect coins to pro- duce pupil dilation, thus admitting more light into the eye and perhaps enhancing the perceived size of the coin.

This proposed mechanism is, of course, entirely speculative. Such a mechanism does, however, suggest several testable hypotheses. First, if the process operates in the manner described there should be a negative correlation between pupil diameter in response to a given stimulus and the recognition threshold of that stimulus. On the basis of preliminary data collected by the authors such a negative correlation is found for words of different emotional connotations. A more definitive evaluation must await the outcome of several experiments, now in progress, dealing with the latency of the pupil response, the relation between artifically manipulated pupil size and recognition threshold, and the relative thresholds of adaptively significant stimuli vs adaptively irrelevant stimuli. 1

\section{References}

BRADLEY, K. The effect of relative word frequency in pairedassociate learning on duration thresholds of nonsense syllables. Unpublished research paper, University of Arkansas, 1965.

BRUNER, J. S., \& GOODMAN, C. C. Value and need as organizing factors in perception. J. abnorm. soc. Psychol., 1947, 42, 33-44.

BYRNE, D. The repression-sensitization scale: rationale, reliability, and validity. J. Pers, 1961, 29, 344-349.

HESS, F. H. Attitude and pupil size. Scient. American, 1965. 212. $46-54$.

HESS, F. H., \& POLT, J. Pupil size as related to interest value of visual stimuli. Science, 1960, 349-350.

MINARD, J, G. Response bias interpretation of perceptual defense: a selective review and an evaluation of recent research. PsychoL Rev., 1965, 72, 74-88.

\section{Note}

1. A more detailed description of the present experiment and the experiments dealing with the relation between pupil size and recognition threshold may be obtained by writing the senior author, Department of Psychology, Memphis State University, Memphis, Tennessee 38111. 